\title{
Asymptomatic meningitis diagnosed by positron emission tomography in a patient with syndrome of inappropriate antidiuretic hormone secretion: a case report
}

\author{
Masanori Hasebe ${ }^{1}$, Jun Shirakawa ${ }^{1,2^{*}} \oplus$, Daisuke Miyashita ${ }^{1}$, Rieko Kunishita ${ }^{1}$, Mayu Kyohara ${ }^{1}$, \\ Tomoko Okuyama ${ }^{1}$, Yu Togashi ${ }^{1}$ and Yasuo Terauchi ${ }^{1}$
}

\begin{abstract}
Background: Syndrome of inappropriate antidiuretic hormone secretion can be caused by arginine-vasopressin-producing tumors or enhanced arginine vasopressin secretion from the posterior pituitary gland due to central nervous system disorders and intrathoracic diseases.

Case presentation: A 53-year-old Asian man was hospitalized with complaints of tremor and hiccups. Laboratory examination revealed findings suggestive of hypotonic hyponatremia due to syndrome of inappropriate antidiuretic hormone secretion. The patient did not complain of headache or photophobia, and showed no signs of meningeal irritation. Positron emission tomography-computed tomography revealed $18 \mathrm{~F}$-fluoro-deoxy-glucose accumulation along the cervical spinal cord, based on which the patient was diagnosed as having aseptic meningitis. The hyponatremia was treated successfully by fluid restriction, and optimum plasma sodium concentration was maintained by tolvaptan administration.

Conclusions: This case underscores the need to consider the possibility of mild meningitis as the cause of syndrome of inappropriate antidiuretic hormone secretion in patients without other identifiable cause.
\end{abstract}

Keywords: Hyponatremia, Aseptic meningitis, SIADH, Vasopressin

\section{Background}

The concentration of sodium ions in the plasma is maintained within an optimum range concurrently with the extracellular fluid volume, to regulate the plasma osmotic pressure. Hyponatremia can be induced by syndrome of inappropriate antidiuretic hormone secretion (SIADH) and cerebral salt-wasting syndrome (CSWS) [1]. SIADH can be caused by arginine vasopressin (AVP)-producing tumors or enhanced AVP secretion from the posterior

\footnotetext{
*Correspondence: jshira@gunma-u.ac.jp

1 Department of Endocrinology and Metabolism, Graduate School of Medicine, Yokohama City University, Yokohama, Japan

Full list of author information is available at the end of the article
}

pituitary gland. The latter is mostly caused by central nervous system disorders and intrathoracic diseases.

Clinical presentations of SIADH are due to hyponatremia and reduced extracellular fluid osmolality, which results in cerebral edema. The rate and severity of hyponatremia and the degree of cerebral edema determine symptoms. Nonspecific and variable symptoms such as general malaise, loss of appetite, and disturbance of consciousness are manifested by SIADH. Due to the cerebral adaptation, the symptoms sometimes remain mild in the chronic phase despite a serum sodium concentration below $120 \mathrm{mmol} / \mathrm{L}$. The diagnosis of SIADH defined by the Schwartz and Bartter clinical criterion original author(s) and the source, provide a link to the Creative Commons licence, and indicate if changes were made. The images or other third party material in this article are included in the article's Creative Commons licence, unless indicated otherwise in a credit line to the material. If material is not included in the article's Creative Commons licence and your intended use is not permitted by statutory regulation or exceeds the permitted use, you will need to obtain permission directly from the copyright holder. To view a copy of this licence, visit http://creativecommons.org/licenses/by/4.0/. The Creative Commons Public Domain Dedication waiver (http://creativeco mmons.org/publicdomain/zero/1.0/) applies to the data made available in this article, unless otherwise stated in a credit line to the data. 
that consists of (1) serum sodium less than $135 \mathrm{mEq} / \mathrm{L}$; (2) decreased plasma osmolality (<275 $\mathrm{mOsm} / \mathrm{kg})$; (3) increased urine osmolality ( $>100 \mathrm{moOsm} / \mathrm{kg}$ ); (4) euvolemia; (5) elevated urine sodium (> $40 \mathrm{mEq} / \mathrm{L}$ ); (6) absence of adrenal insufficiency, hypothyroidism, cardiac failure, or diuretic use; (7) correction of hyponatremia in response to fluid restriction [2]. Since patients with SIADH commonly show hyponatremia with normal fluid volume, a low serum uric acid level $(<5 \mathrm{mg} / \mathrm{dL})$ and a low plasma renin activity ( $<5 \mathrm{ng} / \mathrm{mL} /$ hour) can helpful when considering SIADH. AVP can be produced by either a tumor or the neurohypophysis. Because the secretion of AVP from neurohypophysis is heterogeneous, the response of plasma AVP to osmotic stimulation in SIADH was classified into four subtypes [3]. However, the relationship between the clinical symptoms and those different types of osmoregulatory dysfunction remains uncertain.

We report the case of a patient with SIADH associated with meningitis, but in the absence of the typical symptoms of meningitis. The diagnosis of meningitis was made from evidence of cervical myelitis detected on positron emission tomography and computed tomography (PET-CT) images. The hyponatremia was treated successfully by fluid restriction, and optimum plasma sodium concentration was maintained by tolvaptan administration. Thereafter, the dose of tolvaptan could be reduced, and the drug was discontinued altogether after confirming resolution of the abnormalities on cerebrospinal fluid examination. To the best of our knowledge, this is the first reported case of SIADH secondary to meningitis, the latter diagnosed by 18F-fluoro-deoxyglucose (18F-FDG) PET-CT in the absence of the typical clinical symptoms/signs.

\section{Case presentation}

A 53-year-old Asian man presented to us with a 7-day history of fever and tremor, and was admitted to our hospital. The symptoms had persisted/become worse despite treatment with cefditoren pivoxil and acetaminophen for 6 days, and levofloxacin and loxoprofen for 3 days prior to the hospitalization. Two days prior to admission, he had developed generalized malaise, which was sufficiently severe to cause difficulty in walking, and blood tests, chest X-ray examination, whole-body CT, and head CT had been performed at another hospital. The cause of the patient's symptoms, however, remained unclear. Thereafter, he developed hiccups.

On admission, he complained of persistent generalized fatigue, tremor, and hiccups. He did not have any headache or altered sensorium. His height was $174.5 \mathrm{~cm}$ and body weight was $72.0 \mathrm{~kg}$. His body temperature was $36.5{ }^{\circ} \mathrm{C}$ at admission, and he remained afebrile while in hospital. His blood pressure was $117 / 77 \mathrm{mmHg}$, and pulse rate and respiratory rate were 109 beats/minute and 20 breaths/minute, respectively, both regular rhythm. There were no significant gastrointestinal symptoms, respiratory symptoms, dry skin, or xerostomia. There was no edema or evidence of dehydration. Neurologically, the patient exhibited intention tremor, ataxic gait, and dysmetria on both the finger-nose test and knee-heel tests. Notably, there was no quadriplegia (manual muscle testing revealed full power), sensory disorder, headache, photophobia, or signs of meningeal irritation, including nuchal rigidity, positive Kernig's sign, or positive Brudzinski's sign. Laboratory examinations revealed a white blood cell count (WBC) of $8900 / \mu \mathrm{L}$, red blood cell count of $506 \times 10^{4} / \mu \mathrm{L}$, hemoglobin level of $15.7 \mathrm{~g} / \mathrm{dL}$, and platelet count of $20.3 \times 10^{4} / \mu \mathrm{L}$. Serum C-reactive protein level was $0.04 \mathrm{mg} / \mathrm{dL}$. Blood urea nitrogen level was $15 \mathrm{mg} / \mathrm{dL}$, serum creatinine was $0.79 \mathrm{mg} / \mathrm{dL}$, and estimated glomerular filtration rate (eGFR) was $80.3 \mathrm{~mL} /$ minute $/ 1.73 \mathrm{~m}^{2}$. These results indicated absence of any inflammation or renal dysfunction. Serum electrolyte levels were $\mathrm{Na} 123 \mathrm{mEq} / \mathrm{L}, \mathrm{K} 3.9 \mathrm{mEq} / \mathrm{L}$, and $\mathrm{Cl} 86 \mathrm{mEq} / \mathrm{L}$. Plasma osmolarity was $255 \mathrm{mOsm} / \mathrm{kg} \mathrm{H}_{2} \mathrm{O}$, while urinalysis revealed a urinary $\mathrm{Na}$ level of $87 \mathrm{mEq} / \mathrm{L}$ and urinary osmotic pressure of $691 \mathrm{mOsm} / \mathrm{kg} \mathrm{H}_{2} \mathrm{O}$. The serum $\mathrm{ADH}$ level was $1.6 \mathrm{pg} / \mathrm{mL}$, suggesting that inappropriate secretion of $\mathrm{ADH}$ was responsible for the excessive excretion of sodium and hypotonic hyponatremia. Measurement of the serum hormone levels showed a plasma adrenocorticotropic hormone $(\mathrm{ACTH})$ concentration of $30.7 \mathrm{pg} / \mathrm{mL}$ (normal range 7.4-55.7 pg/mL), cortisol concentration of $14.5 \mu \mathrm{g} / \mathrm{mL}(4.5-21.1 \mu \mathrm{g} / \mathrm{mL})$, thyroidstimulating hormone (TSH) concentration of $0.397 \mu \mathrm{IU} /$ $\mathrm{mL}(0.2-5.0 \mu \mathrm{IU} / \mathrm{mL})$, free thyroxine (FT4) concentration of $1.38 \mathrm{ng} / \mathrm{dL}(0.70-1.48 \mathrm{ng} / \mathrm{dL})$, free triiodothyronine (FT3) concentration of $2.29(1.71-3.71 \mathrm{pg} / \mathrm{mL})$, aldosterone concentration of $98.4 \mathrm{pg} / \mathrm{mL}(29.9-159 \mathrm{pg} / \mathrm{mL})$, and plasma renin activity of $0.9 \mathrm{ng} / \mathrm{mL} /$ hour $(0.3-2.9 \mathrm{ng} / \mathrm{mL} /$ hour). Thus, there was no evidence of adrenal dysfunction. The physical and laboratory findings were consistent with the diagnosis of SIADH.

The results of the chest X-ray examination, fundus photographs, contrast-enhanced whole-body CT, contrast-enhanced head CT, and gadolinium-enhanced head magnetic resonance imaging revealed no potential cause for the SIADH. Serum levels of neuron-specific enolase and progastrin-releasing peptide, both small lung carcinoma makers, were within normal limits, and the T-SPOT.TB test, a test for tuberculosis infection, was also negative. 18F-FDG PET-CT revealed an area of tracer accumulation along the cervical cord (Fig. 1, arrow). Based on this PET-CT finding, meningitis was suspected. Examination of the cerebrospinal fluid (CSF) 


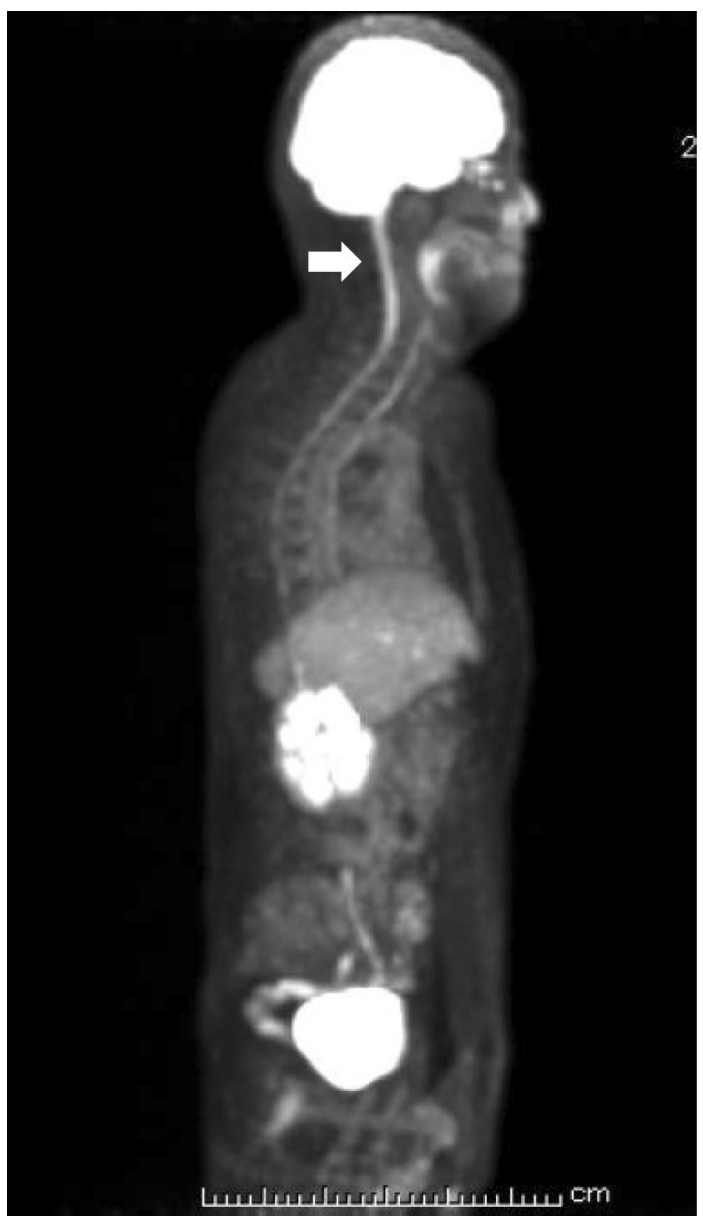

Fig. 1 18F-FDG PET-CT imaging. The arrow indicates the abnormal accumulation of FDG along cervical cord

revealed the following findings: cell count 302 cells $/ 3 \mu \mathrm{L}$ (most were mononuclear cells); total protein $211 \mathrm{mg} / \mathrm{dL}$; albumin $1323 \mu \mathrm{g} / \mathrm{mL}$; glucose $49 \mathrm{mg} / \mathrm{dL} ; \beta 2$-microgroblin $8447 \mathrm{ng} / \mathrm{mL}(440-1240 \mathrm{ng} / \mathrm{mL}) ;$ immunoglobulin G (IgG) $16.6 \mathrm{mg} / \mathrm{dL}(1-3 \mathrm{mg} / \mathrm{dL})$; IgG index $0.61(<0.73)$; adenosine deaminase $10.2 \mathrm{U} / \mathrm{L}(<9.0 \mathrm{U} / \mathrm{L})$; myelin basic protein $175.1 \mathrm{pg} / \mathrm{mL}$ (<102 pg/mL); no oligoclonal band detected. No organisms were detected on Gram staining or culture of the CSF. We considered these findings as being diagnostic of aseptic meningitis or partially treated meningitis, in particular, the findings that the cells were predominantly composed of mononuclear cells and that there was no apparent evidence of bacterial infection or underlying autoimmune diseases such as systemic lupus erythematosus and Behçet's disease as the cause of the meningitis/encephalitis.

Although both intravenous infusion of physiological saline for a day and oral administration of sodium chloride were started, the serum sodium level remained below $125 \mathrm{mEq} / \mathrm{L}$, and improved only after fluid restriction to
$800 \mathrm{~mL} /$ day (Fig. 2, arrow) and initiation of treatment with tolvaptan $7.5 \mathrm{mg} /$ day (Fig. 2). Thereafter, the serum sodium level remained stable (at least until 4 months after admission). Aseptic meningitis was suspected as the cause of the tremor and hiccups. Baclofen $15 \mathrm{mg} /$ day and clonazepam $1 \mathrm{mg} /$ day were administered as symptomatic treatment for the hiccups and tremor, respectively. The hiccups rapidly resolved in response to this treatment, and the tremor tended to improve after the dosage of clonazepam was increased to $2 \mathrm{mg} /$ day. A repeat CSF examination performed on day 22 before discharge of the patient confirmed a reduction of the CSF cell count to $125 / 3 \mu \mathrm{L}$ from $302 / 3 \mu \mathrm{L}$, the latter count recorded in the earlier examination. Thus, our patient showed spontaneous partial remission of the aseptic meningitis. The administration of tolvaptan, baclofen, and clonazepam was gradually reduced after discharge and discontinued by a month after discharge. At 4 months after discharge, the symptomatic improvement was maintained. Throughout the observation period of 4 months, normonatremia was maintained without further treatment with tolvaptan.

\section{Discussion}

SIADH is diagnosed when blood and urine examinations reveal evidence of euvolemic hypotonic hyponatremia and an inappropriately high urine osmolality due to excessive sodium excretion, in the absence of evidence of renal or adrenal dysfunction $[4,5]$. Excessive release of AVP relative to the osmotic pressure from the pituitary by excessive stimulation of the pressure receptors in the carotid sinus or from AVP-producing tumors, including lung cancer, causes SIADH. In the case of ectopic expression of AVP, AVP-producing tumor cells are generally detected in the lung, pancreas, or other tissues. In addition to intrathoracic diseases such as pneumonia and pulmonary tuberculosis, SIADH could often be induced by central nervous system (CNS) causing meningeal stimulation, including subarachnoid hemorrhage, meningitis, and cerebral infarction. The mechanism of AVP hypersecretion from the posterior pituitary secondary to CNS disorder is, however, not clear. In the patient reported herein, the SIADH was considered to have developed as a complication of aseptic meningitis or partially treated meningitis, the diagnosis of which could only be made by PET-CT, as there were no clinical signs/symptoms of meningitis.

In a previous study conducted in infant patients, urinary vasopressin levels were significantly higher in patients with bacterial meningitis than in those with aseptic meningitis [6]. In the patient reported herein with aseptic meningitis, the serum AVP level was relatively low $(1.6 \mathrm{pg} / \mathrm{mL})$. Bacterial meningitis generally provokes 


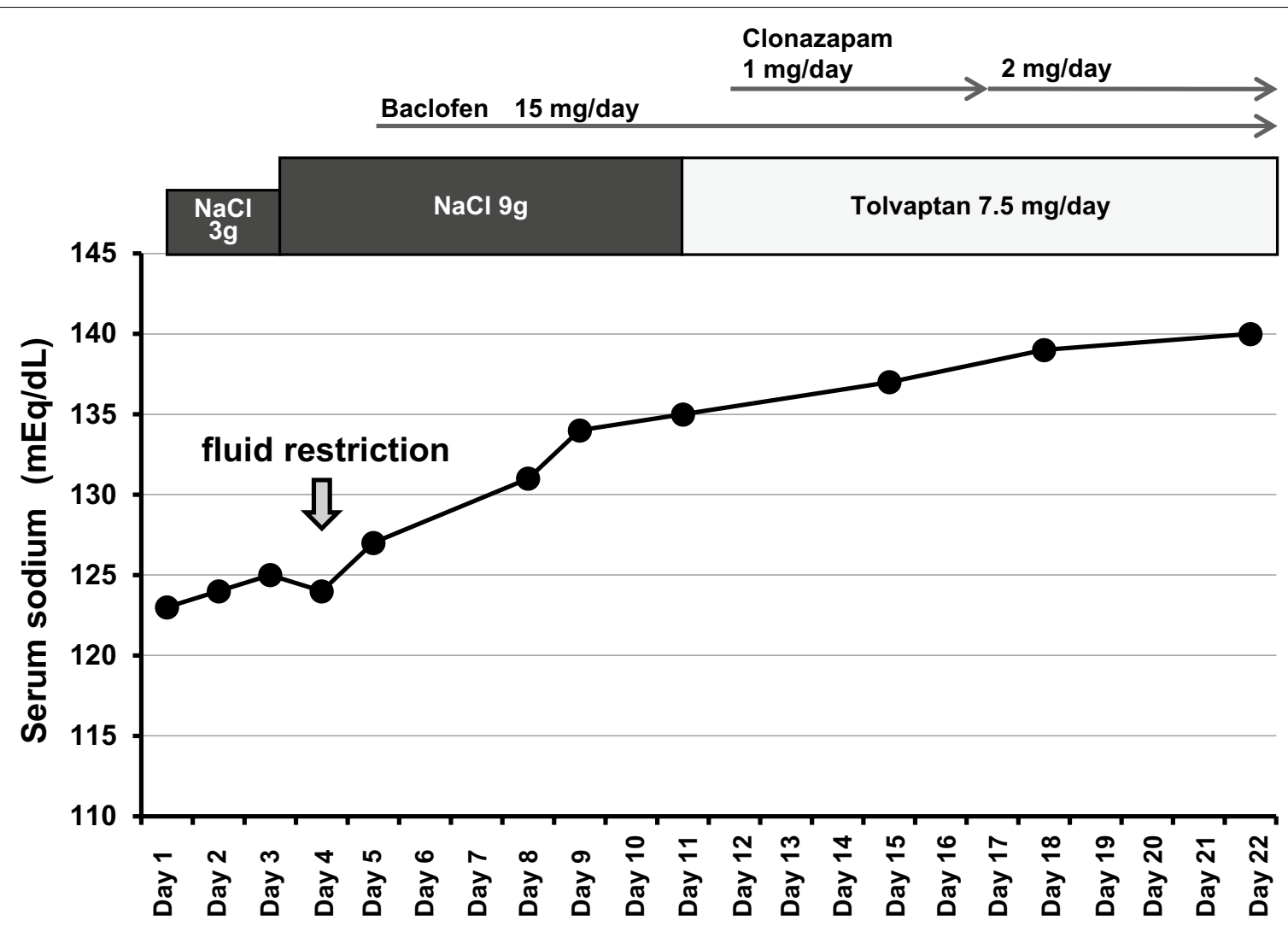

Fig. $\mathbf{2}$ Clinical course. The arrow indicates fluid restriction to $800 \mathrm{~mL} /$ day. The serum sodium level improved after the fluid restriction and remained stable after the start of tolvaptan administration. Baclofen $15 \mathrm{mg} /$ day and clonazepam $1 \mathrm{mg} /$ day were used as symptomatic treatments for the hiccups and tremor; the dose of clonazepam was subsequently increased to $2 \mathrm{mg} /$ day

more severe inflammation and meningeal irritation as compared with meningitis caused by viruses, although definitive differentiation between the two totally relies on examination of the CSF [7]. It is possible that the severity of meningitis is correlated with the AVP secretion levels in SIADH. Patients with meningitis often exhibit hyponatremia with increased urinary sodium excretion because of SIADH and CSWS. No clinical symptoms of CSWS, including dehydration or body fluid loss due to excessive urinary volume and urinary sodium excretion, were observed in our case. In the case of meningitis caused by Pseudomonas aeruginosa, it is known that the patients develop SIADH coinciding with the active phase of meningitis, and that the serum sodium levels become normal with the resolution of meningitis [8]. Other reports of cases of aseptic meningitis with mild encephalitis/encephalopathy associated with a reversible splenial lesion (MERS) also showed resolution of the hyponatremia with improvement of the disease. Our patient also showed restoration of the serum sodium levels to normal range after remission of the aseptic meningitis, indicating that the meningitis was indeed the cause of SIADH.
None of the clinical history, physical examination findings, or findings of biochemical/radiological analysis suggested the involvement of drugs, malignant tumors, intrathoracic diseases, or intracranial lesions in the development of SIADH in our patient. On admission, he had no headache, fever, or any signs of meningeal irritation. 18F-FDG PET-CT identified a spinal lesion, with increased accumulation of FDG in the upper spinal canal. CSF examination revealed findings consistent with the diagnosis of aseptic meningitis or partially treated meningitis. Abnormal FDG accumulation on PET-CT has been reported in patients with malignant tumors or tuberculous meningitis who present with the typical symptoms of meningitis such as fever, headache, nausea, or meningeal irritation [9-12]. We could not identify any case report in the literature in which the diagnosis needed PET-CT, as in our patient. Patients with acquired immune deficiency syndrome presenting with Cryptococcus neoformans meningitis show no typical symptoms of meningitis such as headache, disturbance of consciousness, or clinical features of meningeal irritation [13]. However, in these patients, cryptococcal antigen 
is identified in the CSF, although CSF examination may reveal no biochemical abnormalities. It has been thought that the signs of meningeal irritation are derived from increased intracranial pressure [14]. In our patient, the typical symptoms and signs of meningeal irritation may not have manifested, because the cell count in the CSF and the CSF pressure showed only mild-to-moderate elevation. Hitherto, most cases of SIADH secondary to meningitis have been reported in cases with the typical symptoms and signs of meningitis [15]. Idiopathic forms of SIADH after a series of examinations have often been reported in patients, especially older patients, with hyponatremia $[16,17]$. It is conceivable that, in a considerable number of cases with presumed idiopathic SIADH, the diagnosis of asymptomatic meningitis or partially treated meningitis may have been missed.

In one report of a case of SIADH secondary to bacterial meningoencephalitis associated with traumatic brain injury, treatment with tolvaptan promptly improved the hyponatremia, despite the poor initial response to electrolyte infusion [18]. Aseptic meningitis often shows spontaneous recovery and carries a better prognosis as compared with bacterial meningitis. Therefore, we treated the SIADH in our patient with tolvaptan, which resulted in resolution of the hyponatremia. Because tolvaptan is not yet approved for the treatment of SIADH in Japan at present, appropriate informed consent was obtained from our patient for the treatment. Hiccups has been reported in a case of aseptic meningitis associated with systemic lupus erythematosus [19]. In that case, the symptom resolved immediately after the start of treatment of the meningitis with prednisolone. We thought that the hiccups in our patient could also have been caused by the aseptic meningitis.

\section{Conclusions}

In the present case, the diagnosis of meningitis was made by PET-CT, and we succeeded in the conservative treatment of SIADH with tolvaptan. Empiric antimicrobial therapy is required immediately in cases with suspected bacterial meningitis. Our case report highlights the importance of considering mild-to-moderate meningitis in the differential diagnosis in patients with SIADH without any apparent underlying cause. Our report also underscores the usefulness of 18F-FDG PET-CT imaging for the detection of meningitis in a patient without signs of meningeal irritation. It should be noted that PET-CT is not generally recommended for the diagnosis of meningitis from the viewpoint of the cost-effectiveness of screening. Therefore, we should review the physical, neurological, and biochemical findings carefully and consider the results of CSF examination in SIADH patients with suspected mild meningitis.

\section{Abbreviations}

SIADH: Syndrome of inappropriate antidiuretic hormone secretion; AVP: Arginine vasopressin; CSWS: Cerebral salt-wasting syndrome; PET-CT: Positron emission tomography and computed tomography; FDG: 18F-fluoro-deoxyglucose; CSF: Cerebrospinal fluid.

\section{Acknowledgements}

Not applicable.

\section{Authors' contributions}

$\mathrm{MH}$ and JS wrote the initial draft of the manuscript. MH, JS, and YTe obtained patient consent and was involved in drafting and revising the manuscript. $\mathrm{MH}$ JS, DM, RK, MK, TO, YTo, and YTe participated in the diagnosis and treatment of SIADH. MH and JS contributed to the study concept and design. All authors read and approved the final manuscript.

\section{Funding}

This report received no specific grant from any funding agency in the public, commercial, or not-for-profit sector.

Availability of data and materials

Not applicable.

\section{Declarations}

Ethics approval and consent to participate

Ethical approval was not required by the ethical committee in Yokohama City University.

\section{Consent for publication}

Written informed consent was obtained from the patient for publication of this case report and any accompanying images. A copy of the written consent is available for review by the Editor-in-Chief of this journal.

\section{Competing interests}

The authors declare that they have no competing interests.

\section{Author details}

${ }^{1}$ Department of Endocrinology and Metabolism, Graduate School of Medicine, Yokohama City University, Yokohama, Japan. ${ }^{2}$ Laboratory of Diabetes and Metabolic Disorders, Institute for Molecular and Cellular Regulation (IMCR), Gunma University, 3-39-15 Showa-machi, Maebashi 371-8512, Japan.

Received: 5 August 2019 Accepted: 14 June 2021

Published online: 22 July 2021

References

1. Ellison DH, Berl T. Clinical practice. The syndrome of inappropriate antidiuresis. N Engl J Med. 2007;356:2064-72.

2. Bartter FC, Schwartz WB. The syndrome of inappropriate secretion of antidiuretic hormone. Am J Med. 1967:42:790-806.

3. Robertson GL. Regulation of arginine vasopressin in the syndrome of inappropriate antidiuresis. Am J Med. 2006;119:S36-42.

4. Fenske W, Maier SK, Blechschmidt A, Allolio B, Stork S. Utility and limitations of the traditional diagnostic approach to hyponatremia: a diagnostic study. Am J Med. 2010;123:652-7.

5. Gross P. Clinical management of SIADH. Ther Adv Endocrinol Metab. 2012;3:61-73.

6. Padilla G, Ervin MG, Ross MG, Leake RD. Vasopressin levels in infants during the course of aseptic and bacterial meningitis. Am J Dis Child. 1991;145:991-3.

7. Mount HR, Boyle SD. Aseptic and bacterial meningitis: evaluation, treatment, and prevention. Am Fam Physician. 2017;96:314-22. 
8. Hirano T, Watanabe T, Yano S, Yamamura Y. Case of Pseudomonas aeruginosa meningitis with the syndrome of inappropriate secretion of $\mathrm{ADH}$. Nihon Rinsho. 1973;31:2610-3 ((in Japanese)).

9. Rangan K, Ravina M, Yadav N, Suraj AS, Gambhir S. 18F-FDG PET/CT of tuberculosis meningitis and carotid pseudoaneurysm. Clin Nucl Med. 2017;42:e304-5.

10. Gambhir S, Kumar M, Ravina M, Bhoi SK, Kalita J, Misra UK. Role of (18) F-FDG PET in demonstrating disease burden in patients with tuberculous meningitis. J Neurol Sci. 2016:370:196-200.

11. Heimburger C, Bund C, Namer IJ. FDG PET in intracranial carcinomatous meningitis. Clin Nucl Med. 2016;41:60-1.

12. Renard D, Dufour S, Collombier L, Labauge P. Cerebral FDG-PET hypermetabolism in carcinomatous meningitis. Eur Neurol. 2011;66:332-3.

13. Li A, Li Q, Guo C, Zhang Y. Asymptomatic meningitis and lung cavity in a case of cryptococcosis. Am J Case Rep. 2017;18:1140-4.

14. Nagel A, Graetz D, Schink T, Frieler K, Sakowitz O, Vajkoczy P, Sarrafzadeh A. Relevance of intracranial hypertension for cerebral metabolism in aneurysmal subarachnoid hemorrhage. Clinical article. J Neurosurg. 2009;111:94-101.

15. Hasegawa T, Nakashima A, Ishimaru M, Shima T, Hidaka T, Saito S. Carcinomatous meningitis associated with ovarian cancer complicated by SIADH. Gan To Kagaku Ryoho. 2010;37:739-42 ((in Japanese)).
16. Anpalahan M. Chronic idiopathic hyponatremia in older people due to syndrome of inappropriate antidiuretic hormone secretion (SIADH) possibly related to aging. J Am Geriatr Soc. 2001;49:788-92.

17. Goldstein CS, Braunstein S, Goldfarb S. Idiopathic syndrome of inappropriate antidiuretic hormone secretion possibly related to advanced age. Ann Intern Med. 1983;99:185-8.

18. Graziani G, Cucchiari D, Aroldi A, Angelini C, Gaetani P, Selmi C. Syndrome of inappropriate secretion of antidiuretic hormone in traumatic brain injury: when tolvaptan becomes a life saving drug. J Neurol Neurosurg Psychiatry. 2012;83:510-2.

19. Sugimoto T, Takeda N, Yamakawa I, Kawai H, Tanaka Y, Sakaguchi M, Osawa N, Uzu T, Kashiwagi A. Intractable hiccup associated with aseptic meningitis in a patient with systemic lupus erythematosus. Lupus. 2008;17:152-3.

\section{Publisher's Note}

Springer Nature remains neutral with regard to jurisdictional claims in published maps and institutional affiliations.
Ready to submit your research? Choose BMC and benefit from:

- fast, convenient online submission

- thorough peer review by experienced researchers in your field

- rapid publication on acceptance

- support for research data, including large and complex data types

- gold Open Access which fosters wider collaboration and increased citations

- maximum visibility for your research: over $100 \mathrm{M}$ website views per year

At BMC, research is always in progress.

Learn more biomedcentral.com/submissions 